\title{
Rhabdomyolysis in a Patient Taking Both Oxandrolone for Bodybuilding and Methamphetamine
}

\author{
Michael Krzyzak ${ }^{1}$, Natarajan Elangovan ${ }^{2}$ \\ 1. Medicine, Staten Island University Hospital 2. Department of Psychiatry, Staten Island University Hospital
}

Corresponding author: Michael Krzyzak, mkrzyzakmd@outlook.com

\begin{abstract}
Nonprescription drug use is increasingly prevalent in the United States. We report a case of a 31-year-old male who presented with hallucinations and was found to have rhabdomyolysis. He was consuming oxandrolone for six weeks and ingested methamphetamine the night prior to presentation. With supportive treatment, including intravenous hydration, the patient's mental status returned to baseline and rhabdomyolysis resolved. Our case illustrates the need to understand the interaction between different illicit substances. More research needs to be done to further understand the reactions between different medications as patients consume different combinations of substances.
\end{abstract}

Categories: Emergency Medicine, Internal Medicine, Psychiatry

Keywords: rhabdomyolisis, methamphetamine, polysubstance

\section{Introduction}

Polysubstance use is becoming a common issue when uncovering unknown side effects of nonprescription medication. In the United States, $6.3 \%$ of people have taken nonprescription drugs. In the 18- to 29 -year-old group, the prevalence of polysubstance use is $13.5 \%$ [1]. Herein, we report a patient that presented with acute delusion found to be in rhabdomyolysis after consuming methamphetamine while using testosterone for bodybuilding.

\section{Case Presentation}

A 31-year-old male presented to the emergency room with complaints of unusual behavior at work. He noted that while working at a metal shop, he heard voices and saw unusual figures. The night prior, he was watching a sporting event with friends and took 3,4-methylenedioxymethamphetamine (MDMA). He also uses oxandrolone injections for muscle building. Oxandrolone was started approximately six weeks prior to presentation. He takes no other medication or supplementation.

Received 10/25/2017

Review began 11/02/2017 Review ended 11/10/2017 Published 11/13/2017

(c) Copyright 2017 Krzyzak et al. This is an open access article distributed under the terms of the Creative Commons Attribution License CC-BY 3.0., which permits unrestricted use, distribution, and reproduction in any medium, provided the original author and source are credited.
On presentation, vitals were normal. Mental status was positive for auditory and visual hallucinations. He was confused as per his family but was oriented fully. Physical examination was otherwise unremarkable.

Laboratory findings were significant for a creatine kinase level of $1893 \mathrm{IU} / \mathrm{L}$, creatine kinase-MB of 43.0 ng/mL, aspartate transaminase (AST) 137 IU/L, and alanine transaminase (ALT) 212 IU/L. He received intravenous hydration and haloperidol for agitation. He was admitted to the telemetry unit. Within 24 hours of hospitalization, the mental status returned to baseline. Creatine kinase trended down to $841 \mathrm{IU} / \mathrm{L}$ and creatine kinase-MB to $16.5 \mathrm{IU} / \mathrm{L}$. He was advised not to continue hormone injection or drug use. He was discharged home to follow up with his primary care physician.

\section{Discussion}

Between one and three million people in the United States are on hormonal supplements for bodybuilding [2]. Studies illustrate that up to $5 \%$ of high school students have tried performance-enhancing substances $[2]$.

Medical indications for anabolic steroid use include hypogonadism, catabolic disorders as muscle wasting, growth retardation, tissue healing, cachexia, osteoporosis, aplastic anemia, virile climacteric period, and hepatic carcinoma. Athletes consume steroids for its anabolic properties, which include promoting protein synthesis, positive nitrogen balance, muscle growth, increasing calcium uptake, stimulation of skeletal growth, erythropoiesis, the percentual decrease of body fat, and V-shaped bodybuilding [3].

Anabolic steroid use in bodybuilders is known to cause many side effects. Effects include venous thromboembolism, arterial thromboembolism, disc herniation, hypertrophic cardiomyopathy, dilated cardiomyopathy, hepatocellular carcinoma, renal failure, depression, and suicide thoughts [4]. Oxandrolone 
is metabolized by $17 \alpha$-alkylation, which is hepatotoxic. The elevation in AST and ALT noted in our case can be explained by end-organ damage secondary to oxandrolone [4].

Methamphetamine is known as a psychomotor stimulant, and psychosis is known to last up to several weeks. Effects include violent behavior and paranoid psychosis. Its mechanism of action is directing its effect on the manufacture of dopamine and serotonin causing an alteration in sleep, sexual function, movement disorders, and schizophrenia [5].

Methamphetamine is metabolized by the liver via demethylation, primarily demethylated by cytochrome $\mathrm{P}$ 450 2D (CYP2D6) [6-7]. Similarly, oxandrolone is also metabolized by the liver; unlike other testosterone derivatives, it takes longer to be deactivated by hydroxylation and sulfation [8]. The combination of the two medications produces a synergistic effect causing rhabdomyolysis. It is supported by their common metabolic pathway and both inactivated products are later excreted in urine.

Studies have evaluated the interaction between anesthetic agents and illicit substances, but there is no research on the effects of interaction between illicit substances [9].

\section{Conclusions}

Studies have evaluated the interaction between numerous medications, but more research needs to be performed in order to understand the interaction between illicit substances. Given the polysubstance use in the discussed case, clinicians should be aware of polysubstance use in the community and its effects. As demonstrated in this case, combinations of different illicit substances can result in exaggerated effects of either substance alone and produce dangerous results.

\section{Additional Information \\ Disclosures}

Human subjects: Consent was obtained by all participants in this study. Conflicts of interest: In compliance with the ICMJE uniform disclosure form, all authors declare the following: Payment/services info: All authors have declared that no financial support was received from any organization for the submitted work. Financial relationships: All authors have declared that they have no financial relationships at present or within the previous three years with any organizations that might have an interest in the submitted work. Other relationships: All authors have declared that there are no other relationships or activities that could appear to have influenced the submitted work.

\section{References}

1. Connor JP, Gullo MJ, White A, Kelly AB: Polysubstance use: diagnostic challenges, patterns of use and health. Curr Opin Psychiatry. 2014, 27:269-275. 10.1097/YCO.0000000000000069

2. Sjöqvist F, Garle M, Rane A: Use of doping agents, particularly anabolic steroids, in sports and society . Lancet. 2008, 371:1872-1882. 10.1016/S0140-6736(08)60801-6

3. Mottram DR, George AJ: Anabolic steroids. Baillieres Best Pract Res Clin Endocrinol Metab. 2000, 14:55-69. 10.1053/beem.2000.0053

4. Nieschlag E, Vorona E: Doping with anabolic androgenic steroids (AAS): adverse effects on nonreproductive organs and functions. Rev Endocr Metab Disord. 2015, 16:199-211. 10.1007/s11154-015-93205

5. Robert JM: A primer of drug action: a concise nontechnical guide to the actions, uses, and side effects of psychoactive drugs, revised and updated. Worth Publishers, New York; 2001.

6. Mitler MM, Hajdukovic R, Erman MK: Treatment of narcolepsy with methamphetamine. Sleep. 1993, 16:306-317. 10.1093/sleep/16.4.306

7. Lindsey WT, Stewart D, Childress D: Drug interactions between common illicit drugs and prescription therapies. Am J Drug Alcohol Abuse. 2012, 38:334-343. 10.3109/00952990.2011.643997

8. Berger JR, Pall L, Hall CD, Simpson DM, Berry PS, Dudley R: Oxandrolone in AIDS-wasting myopathy. AIDS. 1996, 10:1657-1662.

9. Pallasch TJ: Anesthetic management of the chemically dependent patient . Anesth Prog. 1992, 39:157-161. 